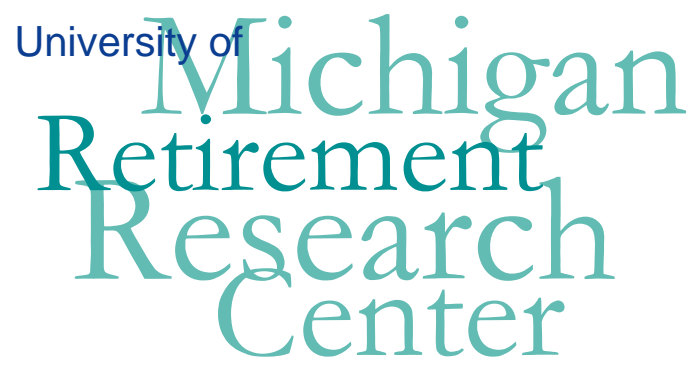

Working Paper

WP 2004-089

\title{
Obesity, Disability, and Movement Onto the Disability Insurance Rolls
}

Richard V. Burkhauser and John Cawley

\begin{tabular}{|l|l|}
\hline $\mathrm{M}$ & $\mathrm{R}$ \\
\hline $\mathrm{R}$ & $\mathrm{C}$ \\
\hline
\end{tabular}$\quad$ Project \#: UM04-08 


\title{
“Obesity, Disability, and Movement Onto the Disability Insurance Rolls”
}

\author{
Richard V. Burkhauser \\ Cornell University \\ John Cawley \\ Cornell University
}

October 2004

\author{
Michigan Retirement Research Center \\ University of Michigan \\ P.O. Box 1248 \\ Ann Arbor, MI 48104
}

\section{Acknowledgements}

This work was supported by a grant from the Social Security Administration through the Michigan Retirement Research Center (Grant \# 10-P-98358-5). The opinions and conclusions are solely those of the authors and should not be considered as representing the opinions or policy of the Social Security Administration or any agency of the Federal Government.

\section{Regents of the University of Michigan}

David A. Brandon, Ann Arbor; Laurence B. Deitch, Bingham Farms; Olivia P. Maynard, Goodrich; Rebecca McGowan, Ann Arbor; Andrea Fischer Newman, Ann Arbor; Andrew C. Richner, Grosse Pointe Park; S. Martin Taylor, Gross Pointe Farms; Katherine E. White, Ann Arbor; Mary Sue Coleman, ex officio 


\title{
Obesity, Disability, and Movement Onto the Disability Insurance Rolls
}

\author{
Richard V. Burkhauser and John Cawley
}

\begin{abstract}
Between the early 1980s and 2002, both the prevalence of obesity and the number of beneficiaries of the Social Security Disability Insurance program doubled. We test whether these trends are related; specifically, we test whether obesity causes disability and movement onto the disability rolls.

We estimate models of instrumental variables using two nationally representative data sets: the Panel Survey of Income Dynamics and the National Longitudinal Survey of Youth, 1979 Cohort. The results are mixed but we find evidence that weight increases the probability of health-related work limitations and the probability of receiving disabilityrelated income. Our results suggest that the failure to treat obesity as endogenous leads to dramatic underestimates of the link between obesity and disability outcomes.
\end{abstract}

\section{Authors' Acknowledgements}

We thank seminar participants at Ohio State University and the 2004 Conference of the Social Security Retirement Research Consortium for their helpful comments. We gratefully acknowledge financial support from the University of Michigan Retirement Research Consortium and the Bronfenbrenner Life Course Center at Cornell University. We thank Shuaizhang Feng for expert research assistance. 


\section{Introduction}

This paper is motivated by two recent trends in the U.S.: a rise in obesity and a rise in disability. The age-adjusted prevalence of obesity -- which is defined as a body mass index (BMI) greater than or equal to thirty - more than doubled from 15 percent during 1976-1980 to 30.4 percent during 1999-2002 (Hedley et al., 2004; Flegal et al., 2002). Over roughly the same period, the number of beneficiaries receiving income from the Social Security Disability Insurance program (DI) doubled from 3.8 million in 1983 to 7.6 million in 2002 (Social Security Administration, 2004). This paper tests whether these trends are related; specifically, we test whether obesity raises the probabilities of employment disability and of movement onto the rolls of DI.

There exists suggestive, but not definitive, evidence on the relationship between obesity and disability. For example, Lakdawalla, Bhattacharya, and Goldman (2004) document that, in the National Health Interview Surveys from 1984 to 1996, rates of disability rose faster among the obese than among the non-obese. Ferraro et al. (2002) found that obesity or becoming obese was subsequently associated with higher levels of upper-body and lower-body disability in the National Health and Nutrition Examination Survey I and its follow-ups.

In several instances recently, the Social Security Administration (SSA) has revised its medical listing of obesity. In 1999, obesity was deleted from the medical listings. In 2000, a Social Security Ruling ensured that obesity would once again be included in the medical listings. In 2002, SSA policy was revised yet again with obesity considered a severe impairment that merits its own medical listing (Federal Register, 
2002). The changing policies of the SSA reflect uncertainty within government about the effect of obesity on disability ${ }^{1}$; this paper documents and quantifies this effect.

There are three possible explanations for the correlation between obesity and disability. First, obesity may in fact cause disability. This is plausible given the evidence that obesity is a risk factor for many chronic diseases (Pi-Sunyer, 2002). Second, the reverse may be true -- disability may cause obesity. Disability is likely to result in a decline in physical activity, which, if not matched with a decline in calorie intake, will result in weight gain. Third, unobserved factors may cause both obesity and disability. One possible such unobserved factor is rate of time discount. People who do not value future outcomes are likely invest less in their health, which may lead to both obesity and employment disability.

Cawley (2000) tested the first hypothesis, that obesity causes employment disability. Using the method of instrumental variables to exploit the genetic (i.e. exogenous) variation in weight between mothers and children, it found little evidence that obesity causes employment disability among young women (aged 16-41) in the National Longitudinal Survey of Youth, 1979 Cohort (NLSY). This paper builds on the previous analysis by expanding the scope of inquiry beyond young mothers to working-age adults

\footnotetext{
${ }^{1}$ The debate over whether obesity is the cause or result of illness and disability is taking place in other government agencies as well. The Equal Employment Opportunity Commission (EEOC) originally mandated that obesity was not a disabling impairment covered by the Americans with Disabilities Act of 1990, but it reversed itself and filed an amicus curae brief supporting the obese plaintiff's claim of ADA protection on grounds of obesity in the 1993 court case Cook v. Rhode Island (Kuss, 1996; Carpenter, 2002). The current EEOC compliance manual states somewhat ambiguously that "Being overweight, in and of itself, is generally not an impairment... except in rare circumstances, obesity is not considered a disabling impairment... On the other hand, severe obesity, which has been defined as body weight more than $100 \%$ over the norm...is clearly an impairment” (U.S. EEOC, 2004). Most recently, in July 2004, the Centers for Medicare and Medicaid Services revised their Coverage Issues Manual to remove a statement that obesity cannot be considered an illness; this language had precluded Medicare and Medicaid from covering obesity treatments unless beneficiaries were suffering from other obesity-related illnesses (U.S. Department of Health and Human Services, 2004). Better understanding the relationship between obesity and disability may help resolve some of the debates over whether obesity should be considered grounds for government-funded disability benefits or medical treatment.
} 
of both genders and examines data from both the NLSY and the Panel Survey of Income Dynamics (PSID).

\section{Methods}

We first estimate linear probability (LP) models of disability as a function of weight; the coefficients will indicate the overall correlation between obesity and disability-related outcomes. This overall correlation reflects both the impact of weight on disability and the impact of disability on weight and the influence of unobserved third variables that affect both weight and disability.

In order to generate a consistent estimate of the causal effect of weight on disability, we estimate two-stage least squares (2SLS) models. Our instrument is the weight of a biological relative; specifically: in the PSID, a child or parent; in the NLSY, a sibling. (The weight of parents is not collected by the NLSY, and the weight of children is collected only for female respondents.) Our identifying assumption has two parts. First, we assume that the weights of children and parents, and the weights of siblings, are highly correlated. This is confirmed by the behavioral genetics literature (e.g. Maes et al., 1997), which is predictable since weight has a large genetic component and a child and a parent, and siblings, share on average half of their genes. Results from the firststage regression confirm that sibling weight is a powerful instrument for respondent weight. The F statistic associated with the hypothesis that the first-stage coefficients on the instruments are jointly equal to zero is, in each case, many times the minimum of 10 suggested by Staiger and Stock (1997). (These F statistics are reported in detail in the footnotes of the tables of results.) 
The second part of the identifying assumption is that the only way that the weight of a child or sibling is correlated with the respondent's disability status is through its correlation with the respondent's weight. In other words, the weight of a relative is uncorrelated with the residual in the disability equation. One might be concerned that the non-genetic variation in a relative's weight is correlated with the respondent's disability status because of habits learned in the household. However, to date studies have failed to detect any effect of common household environment on body weight (Grilo and Pogue-Geile, 1991).

\section{Data}

We use data from two longitudinal, nationally representative datasets: The Panel Survey of Income Dynamics (PSID) and the National Longitudinal Survey of Youth, 1979 Cohort (NLSY). In each sample we study respondents of prime working age; we drop those under age 25 because many are enrolled in school. In this section, we describe the relevant features of, and variables in, each dataset.

\section{Panel Study of Income Dynamics (PSID)}

The Panel Study of Income Dynamics (PSID) is a nationally representative, longitudinal survey of individuals and the families in which they reside. The sample size has grown from 4,800 families in 1968, the first year of the study, to more than 7,000 families in 2001. In order to easily compare the PSID results to those of the NLSY, we limit the PSID sample to the same maximum age as in the NLSY: 44 years old.

The PSID collected information on respondents’ height and weight in 1986, 1999, and 2001. Data from these three years were pooled to create the sample for this paper. 
The PSID does not ask whether women are pregnant at the time of interview. While it may be possible to determine this retrospectively based on children's ages, we have not yet done this. As a result, some of the variation in weight among PSID women may be due to pregnancy.

For our 2SLS analysis, we use as an instrument the BMI of the PSID respondent's first biological child, controlling for the child's age and gender. The PSID collected data on the height and weight of children in the Child Development Supplements I (conducted in 1997) and II (conducted in 2002-2003). Child weight was reported by the parent in CDS I and measured in CDS II; child height was measured in both supplements. If parents' weight is available, we also control for mother's BMI and age, and father's BMI and age. Parental weight was not collected as part of any special supplement; it is sometimes available as a natural byproduct of the PSID design, which follows households that spin off from the original 1968 households.

\section{National Longitudinal Survey of Youth, 1979 Cohort}

The National Longitudinal Survey of Youth (NLSY), designed to represent the entire population of American youth, consists of a randomly chosen sample of 6,111 U.S. civilian youths, a supplemental sample of 5,295 randomly chosen minority and economically disadvantaged civilian youths, and a sample of 1,280 youths on active duty in the military. All sample members were between fourteen and twenty-two years of age when the first annual interview was conducted in 1979. Since 1994, interviews have been conducted every two years.

The NLSY recorded the self-reported weight of respondents in 1981, 1982, 1985, 1986, 1988, 1989, 1990, 1992, 1993, 1994, 1996, 1998, and 2000. Data from these 
thirteen years were pooled to create the sample used in this paper. Reported height was recorded in 1981, 1982, and 1985; given that respondents were between the ages of 20 and 27 in 1985, height in 1985 was assumed to be the respondents' adult height. Weight may be affected by pregnancy, so all females who are pregnant at the time that they report their body weight are dropped from the sample.

For our instrumental variables analysis, we will use as an instrument the BMI of the NLSY respondent's sibling, controlling for the sibling's age and gender. Sibling weight was not collected as part of any special supplement; instead, the NLSY survey design involved interviewing every age-eligible child in each randomly selected household. 2,862 households included more than one NLSY respondent, and 5,914 NLSY respondents have at least one sibling in the sample (Bureau of Labor Statistics, 2003). A different observation of BMI from the same sibling is used as an instrument for each observation of respondent weight.

Cawley (2000) used as an instrument the weight of a child to study whether obesity causes employment disability. We prefer to use sibling weight rather than child weight as an instrument for two reasons. First, child weight was recorded only for female respondents whereas sibling data is available for both genders. Second, the NLSY did not begin to record child weight until 1986, while sibling data is available for the entire survey history.

\section{Measures of Weight}

Weight is self-reported in both the PSID and the NLSY. There are welldocumented biases in how individuals report their weight (e.g. Rowland, 1989). In order to correct for this reporting error, which has the potential to bias regression coefficients, 
we use the method of Lee and Sepanski (1995) and Bound et al. (2002); specifically, we use the NHANES III data as validation data. NHANES III is ideal for this purpose because it contains both self-reports and measures of actual height and weight. By regressing reported on actual weight in NHANES III, "transporting” the coefficients to the PSID and NLSY, and multiplying them by the self-reported values, we generate measures of weight corrected for reporting error. We will use three measures of weight in this paper: weight in pounds (controlling for height in inches), BMI (calculated as weight in kilograms divided by height in meters squared), and an indicator variable that equals one if the respondent's BMI meets the clinical definition of obesity (BMI greater than or equal to 25), and zero otherwise. Ramsey RESET tests indicate that the hypothesis that disability outcomes are linear in weight can be rejected. ${ }^{2}$ We capture nonlinearities in weight using an indicator variable for obesity; in other words, we assume that the clinical cutoff for when obesity begins is also the cutoff for when body weight impacts disability. All three measures of weight are corrected for reporting error.

\section{Measures of Disability}

Disability is an elusive concept to measure since it reflects both health-based impairments and the social environment. We utilize two measures of disability. First, we follow the strategy suggested by Burkhauser, Houtenville and Wittenberg (2003) and use a self-reported work limitation measure of disability. Specifically, respondents in both the PSID and the NLSY are asked whether their health limits the type/kind or amount of work that they can do for pay. Respondents who answer yes to either are coded as disabled under this first measure. Second, we measure disability by receipt of income

\footnotetext{
${ }^{2}$ The Ramsey RESET test consists of adding to the set of regressors BMI raised to the second, third, and fourth power; see Ramsey (1969). An F test of the joint statistical significance of the coefficients on these variables indicates that one can reject the hypothesis of linearity of the outcomes in weight.
} 
from the Veterans Administration, Workers Compensation, or Social Security Disability Insurance; all three sources reflect work limitations in working-age samples. An important difference between the PSID and the NLSY is that PSID respondents are asked if they received income from such sources, while NLSY respondents are asked if they or their spouse received such income. This increases the likelihood of false positives when assigning disability status to NLSY respondents; for example: an NLSY respondent who has no work limitations but whose spouse is disabled and receives DI will be coded by us as disabled. The exact wording of the work limitation and disability income receipt questions in the PSID and NLSY is provided in the Appendix.

\section{Other Regressors}

Disability will be modeled as a function of body weight, controlling for the following variables: highest grade completed, age, number of children in household, and indicator variables for marital status, region of residence, black and Hispanic. Models are estimated separately by gender.

\section{Results}

Results relating to work limitations are presented in Table 1 for men and Table 2 for women. In each table, results from twelve regressions are presented. From left to right, in separate columns, are presented results from linear probability models estimated using PSID data, 2SLS models estimated using PSID data, linear probability models estimated using NLSY data, and 2SLS models estimated using NLSY data. In each of these four columns are presented results from three regressions, each using one of the three measures of body weight: weight in pounds (controlling for height in inches), BMI, 
and an indicator variable for obesity. Results from the PSID and NLSY are presented in the same tables to make it easy to compare results across datasets. Each cell of the table lists a coefficient and the associated standard errors in parentheses.

\section{Work Limitations}

Tables 1 and 2 contain results for regressions in which the dependent variable is an indicator for whether the respondent reports that health limits the type or amount of work they can do. Table 1 indicates that there is little overall correlation between obesity and work limitations for men; in the linear probability results contained in columns 1 and 3, no coefficient on any weight variable is statistically significant. However, the point estimates of the 2SLS coefficients are considerably larger than the linear probability coefficients. For example, the LP coefficient on pounds is .0001 in both the PSID and NLSY, but the 2SLS coefficient is .0014 in the PSID and .0007 in the NLSY. The 2SLS coefficient on BMI is ten times larger than the LP coefficient in the PSID results, and fifteen times larger in the NLSY. For the obesity indicator, the 2SLS coefficients are also many times larger than the LP coefficients. While the 2SLS coefficients are consistently much larger than those from LP models, the 2SLS coefficients are statistically significant only for the NLSY; the lack of statistical significance in the PSID is likely due to its modest sample size. The magnitude of the 2SLS coefficients for the NLSY suggests that the probability that a man reports work limitations rises 0.7 percentage points with an extra ten pounds of weight and rises 5.38 percentage points if the man is obese. The magnitude of the impact of male obesity on work limitations is equivalent to the effect of aging 19.8 years or losing 8.9 years of education. Overall, the results are mixed but there 
is some evidence that body weight in general, and obesity in particular, raises the probability of work limitations among men.

Analogous results for women are presented in Table 2. For women in both samples there is a positive and significant correlation between weight and work limitations in the linear probability models. In the PSID, the coefficients on weight estimated by 2SLS are much larger than those estimated by LP. The 2SLS results imply that an extra ten pounds of weight raises the probability of work limitations by 1.6 percentage points. In the NLSY, the 2SLS coefficients on the weight variables are not statistically significant. The 2SLS coefficients on pounds and BMI are slightly smaller than the LP coefficients, while the 2SLS coefficient on obesity is more than 50 percent larger than the LP coefficient, but the 2SLS coefficient on obesity is not statistically significant. It is curious that the 2SLS coefficients on weight are significant in the smaller PSID sample but not in the much larger NLSY sample, but the significance of the 2SLS coefficients in the PSID sample, combined with the positive and statistically significant LP coefficients in both samples, suggest that weight may increase the probability of work limitations in women.

\section{Disability Income Receipt}

Tables 3 and 4 contain results for regressions in which the dependent variable is an indicator for whether the respondent (in the NLSY, the respondent or spouse) received disability income. Columns 1 and 3 of Table 3 indicate mixed evidence as to whether the overall correlation of obesity and disability income receipt is positive for men. In both the PSID and NLSY, the coefficient on BMI is not statistically significant, but that on obesity is positive and significant. The coefficient on pounds is not significant for the 
PSID, but is significant for the NLSY. The LP estimates suggest the probability of receiving disability income is higher among the obese by 2.13 percentage points (PSID) or 0.8 percentage points (NLSY). Columns 2 and 4 list the 2SLS coefficients. No coefficient on any weight variable is significant for the PSID sample, but this may be due to IV raising standard errors since the 2SLS point estimates are at least as large as those from LP. In contrast, each 2SLS coefficient on a weight variable is statistically significant in the NLSY. The probability of receiving disability income is raised by 0.7 percentage points for a ten-pound gain in weight, and is raised by 6.92 percentage points by obesity. The magnitude of the impact of male obesity on the probability of receiving disability income is equivalent to the effect of losing 15.9 years of education (the conditional effect of age is so small in this regression that the obesity impact is equivalent to aging 1,926 years).

Table 4 contains the analogous results for women. In general, the LP results presented in columns 1 and 3 reveal a stronger correlation between disability income receipt and body weight for women than we saw for men in Table 3. Moreover, each 2SLS coefficient on weight is statistically significant and positive for women. The 2SLS results indicate that a ten-pound gain in weight raises the probability of receiving disability income by 1 percentage point (PSID) or 0.5 percentage points (NLSY). Obesity raises the probability of receiving disability income by 9.21 percentage points (PSID) or 5.64 percentage points (NLSY). Among NLSY females, the magnitude of the impact of obesity on the probability of receiving disability income is equivalent to the effect of aging 31.5 years or losing 16.7 years of education. 
We also investigated whether obesity and body weight were correlated with more long-term disability. To this end, we created new dependent variables that reflect whether an individual had health limitations for at least two years, and whether the respondent received disability income for at least two years. These variables are identical to the previous dependent variables, with the exception that they reflect two years of disability status rather than instantaneous disability status. The results are presented in Tables 5-8. In general, weight appears uncorrelated with two-year work limitations; no 2SLS coefficient on weight is statistically significant for men in Table 5 or women in Table 6. Moreover, the results in Table 7 indicate that we cannot reject the hypothesis that weight is uncorrelated with two-year disability income receipt for men. For NLSY women in Table 8, however, each 2SLS coefficient on weight is statistically significant and positive. The probability that an NLSY woman received disability income for the last two years is raised by 0.3 percentage points by a ten-pound gain, and by 3.67 percentage points by obesity.

\section{Summary}

This paper uses the method of instrumental variables to test the hypothesis that weight causes employment disability. While the results are mixed, there is some evidence that weight increases the probability of health-related work limitations and the probability of receiving disability-related income. Our results suggest that the failure to treat obesity as endogenous leads to dramatic underestimates of the link between obesity and disability outcomes. 
Tests indicate that the relationship between body weight and disability is nonlinear; as a result, our preferred estimates are those that use an indicator variable for obesity as the measure of weight. Linear probability model results for the NLSY suggest that obesity is associated with a rise in the probability of receiving disability income of 1.17 percentage points for women and 0.8 percentage points for men; however, the method of 2SLS indicates that obesity actually raises this probability by 5.64 percentage points for women and 6.92 percentage points for men. Results for the PSID are consistent with those for the NLSY but given the PSID’s sample size the coefficients are not always statistically significant. An important implication of these results is that the causal impact of obesity on disability income receipt is considerably stronger than one would conclude from the overall correlation between the two.

A similar pattern is found for self-reported work limitations: the causal effect as measured by 2SLS is greater than the overall effect measured by LP models. However, the method of 2SLS raises standard errors such that most of the 2SLS coefficients are not statistically significant. The exception is for males in the NLSY, for whom obesity raises the probability of self-reported work limitations by 5.38 percentage points.

This analysis underscores the importance of conducting parallel analyses in complementary data sets. Even though the NLSY and PSID are both nationally representative and were both collected during the 1980s and 1990s, even though we estimated models with identical sets of regressors for the same age ranges, we occasionally find different results for the two samples. Sometimes the same coefficient is significant in one dataset and not another (which may be partly due to differences in sample size), and sometimes the magnitude of the point estimates differs considerably 
across datasets. Some of this variation may be attributable to the following differences across datasets: 1) use of slightly different instruments: in the NLSY we use the weight of a sibling as an instrument whereas in the PSID we use the weight of a child and/or parent as an instrument; 2) we have not yet identified pregnant women in the PSID; 3) the disability income question is specific to the respondent in the PSID but also covers the spouse in the NLSY. The fact that even nationally representative datasets collected over similar time periods can generate results that differ in important ways underscores the need to test hypotheses using multiple datasets in order to determine which results are truly robust.

The finding that obesity causes disability will permit more accurate projections of future DI applications and caseloads. The prevalence of obesity is expected to continue to rise (Flegal et al., 1998), suggesting that, all else equal, DI applications and caseloads will likely continue to rise.

Understanding the contribution of obesity to disability will also permit more accurate estimates of the total costs of obesity. Recent calculations of the cost of obesity (e.g. Wolf and Colditz, 1998) do not correct for the endogeneity of weight, and as a result, underestimate the impact of obesity on disability and underestimate the total costs of obesity. 


\section{Works Cited}

Bound, John, Charles Brown, and Nancy Mathiowetz. 2002. "Measurement Error in Survey Data." in Handbook of Econometrics, volume 5, ed. James Heckman and Ed Leamer. New York: Springer-Verlag.

Bureau of Labor Statistics, U.S. Department of Labor. 2003. NLS Handbook, 2003, U.S. Department of Labor: Washington DC.

Burkhauser, Richard V., Mary C. Daly, Andrew J. Houtenville and Nigar Nagris. 2002. "Self-Reported Work-Limitation Data: What They Can and Cannot Tell Us." Demography, 39(3): 541-555.

Burkhauser, Richard V., Andrew J. Houtenville and David C. Wittenburg. 2003. “A User's Guide to Current Statistics on the Employment of People with Disabilities,” in David C. Stapleton and Richard V. Burkhauser (Eds.) The Decline in the Employment of People with Disability: A Policy Puzzle. W.E. Upjohn Institute for Employment Research: Kalamazoo, MI.

Carpenter, Christopher. 2002. “The Impact of Employment Protection for Obese People.” Unpublished manuscript.

Cawley, John. 2000. “An Instrumental Variables Approach to Measuring the Effect of Body Weight on Employment Disability.” Health Services Research, 35(5 Part II): 1159-1179.

Colditz, G. 1999. "Economic costs of obesity and inactivity.” Medicine and Science in Sports and Exercise 31(Suppl): S663-S667.

Federal Register. 2002. "Social Security Ruling, SSR 02-1p; Titles II and XVI: Evaluation of Obesity.” 67(177), September 12: 57859-57864.

Ferraro, Kenneth F., Ya-ping Su, Randall J. Gretebeck, David Black, and Stephen F. Badylak. 2002. "Body Mass Index and Disability in Adulthood: A 20-Year Panel Study,” American Journal of Public Health, 92(5): 834-840.

Field, Alison E., Joaquin Barnoya, and Graham A. Colditz. 2002. "Epidemiology and Health and Economic Consequences of Obesity.” In Wadden, Thomas A. and Albert J. Stunkard (eds.) Handbook of Obesity Treatment, New York: Guilford Press.

Finkelstein E, Fiebelkorn I., and Wang, G. 2003. "National Medical Spending Attributable to Overweight and Obesity: How Much and Who’s Paying?” Health Affairs, W3: 219-226.

Flegal, Katherine M., Margaret D. Carroll, Cynthia L. Ogden, and Clifford L. Johnson. 2002. "Prevalence and Trends in Obesity Among U.S. Adults, 1999-2000." JAMA. 288(14): 1723-1727.

Flegal, K.M., M. D. Carroll, R. J. Kuczmarski, and C. L. Johnson. 1998. “Overweight and Obesity in the United States: Prevalence and Trends, 1960-1994.” International Journal of Obesity, 22(1): 39-47. 
Hedley, A.A., C.L. Ogden, C.L. Johnson, M.D. Carroll, L.R. Curtin, and K.M. Flegal. 2004. "Prevalence of Overweight and Obesity Among US Children, Adolescents, and Adults, 1999-2002.” JAMA, 291(23): 2847-2850.

Koplan, J.P. and W. H. Dietz. 1999. “Caloric Imbalance and Public Policy.” JAMA, 282(16): 1579-1581.

Kortt, M., Langley, P., and Cox, E. 1998. “A review of cost-of-illness studies on obesity.” Clinical Therapeutics 20: 772-779.

Kuss, Christine L. 1996. “Absolving a Deadly Sin: A Medical and Legal Argument for Including Obesity as a Disability Under the Americans with Disabilities Act." Journal of Contemporary Health Law and Policy, 12: 563.

Lakdawalla, Darius N., Jayanta Bhattacharya, and Dana P. Goldman. 2004. "Are the Young Becoming More Disabled?” Health Affairs, 23(1): 168-176.

Lee, Lung-fei and Jungsywan H. Sepanski. 1995. "Estimation of Linear and Nonlinear Errors-in-Variables Models Using Validation Data.” Journal of the American Statistical Association, 90(429): 130-40.

Maes, Hermine H.M., M. C. Neale, and L. J. Eaves. 1997. "Genetic and Environmental Factors in Relative Body Weight and Human Adiposity.” Behavior Genetics, 27, 4: 325-351.

Manson, Joann E., Patrick J. Skerrett, and Walter C. Willett. 2002. “Epidemiology of Health Risks Associated with Obesity.” In Fairburn, Christopher G. and Kelly D. Brownell, Eating Disorders and Obesity: A Comprehensive Handbook, $2^{\text {nd }}$ Edition. (Guilford Press: New York).

Mokdad, Ali H., James S. Marks, Donna F. Stroup, and Julie L. Gerberding. 2004. “Actual Causes of Death in the United States, 2000.” JAMA, 291(10):1238-1245.

Murphy, K.M. and R. H. Topel. 1985. "Estimation and Inference in Two-Step Econometric Models.” Journal of Business and Economic Statistics 3(4), 1985: 370-379.

Narbro, K., E. Jonsson, B. Larsson, H. Waaler, H. Wedel, and L. Sjostrom. 1996. "Economic Consequences of Sick-Leave and Early Retirement in Obese Swedish Women.” International Journal of Obesity and Related Metabolic Disorders, 20(10): 895-903.

Newey, W. K. 1987. "Efficient Estimation of Limited Dependent Variable Models with Endogenous Explanatory Variables.” Journal of Econometrics, 36(3): 231-50.

Pi-Sunyer, F. Xavier. 2002. "Medical Complications of Obesity in Adults.” In Fairburn, Christopher G. and Kelly D. Brownell, Eating Disorders and Obesity: A Comprehensive Handbook, $2^{\text {nd }}$ Edition. (Guilford Press: New York).

Ramsey, J.B. 1969. “Tests for Specification Error in Classical Linear Least Squares Regression Analysis.” Journal of the Royal Statistical Society, Series B 31: 350371.

Rissanen, A., M. Heliovaara, P. Knekt, A. Reunanen, A. Aromaa, and J. Matela. 1990. "Risk of Disability and Mortality Due to Overweight in a Finnish Population." British Medical Journal, 301: 835-837.

Social Security Administration. 2004a. "Social Security Beneficiary Statistics." Actuarial Publications. World wide web content. Accessed July 22, 2004. http://www.ssa.gov/OACT/STATS/OASDIbenies.html 
Social Security Administration. 2004b. "Selected Data from Social Security's Disability Program.” Actuarial Publications. World wide web content. Accessed July 22, 2004. http://www.ssa.gov/OACT/STATS/dibStat.html

Stapleton, David C. and Richard V. Burkhauser (Eds.). 2003. The Decline in the Employment of People with Disabilities: A Policy Puzzle. W.E. Upjohn Institute for Employment Research: Kalamazoo, MI.

Sturm R. 2002. "The Effects of Obesity, Smoking, and Drinking on Medical Problems and Costs." Health Affairs 21(2): 245-253.

U.S. Department of Health and Human Services. 2004. "HHS Announces Revised Medicare Obesity Coverage Policy.” Press Release. July 15. World wide web content. Accessed July 22, 2004. http://www.hhs.gov/news/press/2004pres/20040715.html

U. S. Equal Employment Opportunity Commission. 2004. "Compliance Manual Section 902: Definition of the Term Disability.” World wide web content. Accessed July 22, 2004. http://www.eeoc.gov/policy/docs/902cm.html

Wolf, A. and Colditz, G. 1998. "Current estimates of the economic cost of obesity in the United States.” Obesity Research 6: 97-106. 


\section{Appendix: Wording of Questions on Disability \\ In the PSID and NLSY79}

\section{Health-related work limitations \\ PSID:}

Do you (HEAD) have any physical or nervous condition that limits the type of work or the amount of work you can do?

Note: if respondents answer yes to the above question they are coded as having healthrelated work limitations.

\section{NLSY79:}

(Are you/Would you be) limited in the kind of work you (could) do on a job for pay because of your health?

(Are you/Would you be) limited in the amount of work you (could) do because of your health?

Note: if respondents answer yes to either of the above questions they are coded as having health-related work limitations.

\section{Receipt of disability-related income \\ PSID:}

Number of Months (YEAR) Head Received (Supplemental Security Income / Social Security Disability / Veterans Administration / Workers Compensation).

Note: each of the above sources is asked in a different question. Our variable on receipt is coded as 1 if the respondent received income from any of these sources in any month of the specified calendar year.

\section{NLSY79:}

During (PREVIOUS CALENDAR YEAR), did you (or [Spouse/partner's name]) receive any (other) veterans' benefits, worker's compensation, disability payments, or payments from social security?

Note: our variable on receipt is coded as 1 if the respondent or spouse/partner received income from any of these sources in the specified calendar year. This question differs from that asked in the PSID in that the NLSY inquires about disability income receipt by either the respondent or their spouse, whereas the PSID asks only about receipt by the respondent. 


\section{Table 1:}

Work Limitations, Males

\begin{tabular}{lcccc} 
& \multicolumn{2}{c}{ PSID } & \multicolumn{2}{c}{ NLSY79 } \\
\cline { 2 - 5 } & LP & 2SLS & LP & 2SLS \\
\hline Weight in Pounds & .0001 & .0014 & .0001 & $.0007^{*}$ \\
& $(.0002)$ & $(.001)$ & $(.0001)$ & $(.0003)$ \\
Height in Inches & .0005 & -.0072 & -.0015 & $-.0051^{*}$ \\
& $(.0027)$ & $(.0068)$ & $(.0013)$ & $(.0021)$ \\
& & & & \\
\hline BMI & .0009 & .01 & .0003 & $.0045^{*}$ \\
& $(.0014)$ & $(.0074)$ & $(.0005)$ & $(.0020)$ \\
\hline Indicator: Obesity & .0197 & .1498 & .0058 & $.0538 \#$ \\
& $(.0155)$ & $(.0999)$ & $(.0049)$ & $(.0280)$ \\
\hline Number of Obs & 1,827 & 1,827 & 18,969 & 18,969
\end{tabular}

Notes:

1) Dependent variable is an indicator that equals 1 if the person has physical conditions that limit type or amount of work, and equals 0 otherwise.

2) Listed are coefficients and standard errors in parentheses

3) \# stands for significance at $10 \%$ level, * stands for significance at $5 \%$ level, ${ }^{* *}$ stands for significance at $1 \%$ level.

4) Other variables that are included in the regressions are: Black dummy, Hispanic dummy, schooling, age, number of children, marriage dummies, region dummies.

5) Notes on 2SLS regressions:

a) PSID: Instruments used are: biological children's age, sex and BMI, whether children's information is missing, father's age and BMI, whether father's information is missing, mother's age and BMI, whether mother's information is missing. The F statistic and change in R2 in the first stage regressions are: 61.2 and 0.3 for weight in pounds, 60.6 and 0.04 for BMI, and 40.8 and .03 for the obesity indicator.

b) NLSY: Instruments used are: sibling BMI, sibling age and gender. The F statistic and change in R2 in the first stage regressions are: 76.5 and .05 for weight in pounds, 77.9 and .06 for BMI, and 43.5 and .04 for the obesity indicator.

6) The sample is restricted to people aged 25 to 44 . 
Table 2:

Work Limitations, Females

\begin{tabular}{lcccc} 
& \multicolumn{2}{c}{ PSID } & \multicolumn{2}{c}{ NLSY79 } \\
\cline { 2 - 5 } & LP & 2SLS & LP & 2SLS \\
\hline Weight in Pounds & $.0006^{* *}$ & $.0016 \#$ & $.0004^{* *}$ & .0003 \\
& $(.0002)$ & $(.0009)$ & $(.0001)$ & $(.0003)$ \\
Height in Inches & & & & \\
& -.0008 & -.0046 & -.0024 & -.0019 \\
& $(.0025)$ & $(.0041)$ & $(.0015)$ & $(.0019)$ \\
\hline BMI & & & & \\
\hline Indicator: Obesity & $.0302^{*}$ & .0757 & $.0235^{* *}$ & .0363 \\
& $(.0129)$ & $(.0886)$ & $(.0052)$ & $(.0334)$ \\
\hline Number of Obs & 2,250 & 2,250 & 16,372 & 16,372
\end{tabular}

Notes:

1) Dependent variable is an indicator that equals 1 if the person has physical conditions that limit type or amount of work, and equals 0 otherwise.

2) Listed are coefficients and standard errors in parentheses

3) \# stands for significance at $10 \%$ level, * stands for significance at $5 \%$ level, ** stands for significance at $1 \%$ level.

4) Other variables that are included in the regressions are: Black dummy, Hispanic dummy, schooling, age, number of children, marriage dummies, region dummies.

5) Notes on 2SLS regressions:

a) PSID: Instruments used are: biological children's age, sex and BMI, whether children's information is missing, father's age and BMI, whether father's information is missing, mother's age and BMI, whether mother's information is missing. The F statistic and change in R2 in the first stage regressions are: 61.1 and 0.04 for weight in pounds, 61.8 and 0.04 for BMI, and 38.1 and .02 for the obesity indicator.

b) NLSY: Instruments used are: sibling BMI, sibling age and gender. The F statistic and change in R2 in the first stage regressions are: 98.1 and .05 for weight in pounds, 99.0 and .05 for BMI, and 73.9 and .04 for the obesity indicator.

6) The sample is restricted to people aged 25 to 44 . 
Table 3:

Received Disability Income, Males

\begin{tabular}{lcccc} 
& \multicolumn{2}{c}{ PSID } & \multicolumn{2}{c}{ NLSY79 } \\
\cline { 2 - 5 } & LP & 2SLS & LP & 2SLS \\
\hline Weight in Pounds & .0002 & .0002 & $.0001 \#$ & $.0007^{* *}$ \\
& $(.0001)$ & $(.0006)$ & $(.0001)$ & $(.0003)$ \\
Height in Inches & .0008 & .0009 & -.0004 & -.0037 \\
& $(.0017)$ & $(.0041)$ & $(.0010)$ & $(.0018)$ \\
& & & & \\
\hline BMI & .0014 & .0017 & .0007 & $.0045^{* *}$ \\
& $(.0009)$ & $(.0043)$ & $(1.59)$ & $(.0017)$ \\
\hline Indicator: Obesity & $.0213^{*}$ & .0343 & $.0080 \#$ & $.0692^{* *}$ \\
& $(.01)$ & $(.0587)$ & $(.0046)$ & $(.0260)$ \\
\hline Number of Obs & 1,827 & 1,827 & 19,502 & 19,502
\end{tabular}

Notes:

1) Dependent variable is an indicator that equals 1 if the person received disability income, veteran's benefits, or workers' compensation, and equals 0 otherwise (in NLSY79, it also equals one if respondent's spouse received income through any of these sources).

2) Listed are coefficients and standard errors in parentheses

3) \# stands for significance at $10 \%$ level, * stands for significance at $5 \%$ level, ** stands for significance at $1 \%$ level.

4) Other variables that are included in the regressions are: Black dummy, Hispanic dummy, schooling, age, number of children, marriage dummies, region dummies.

5) Notes on 2SLS regressions:

a) PSID: Instruments used are: biological children's age, sex and BMI, whether children's information is missing, father's age and BMI, whether father's information is missing, mother's age and BMI, whether mother's information is missing. The F statistic and change in R2 in the first stage regressions are: 61.2 and 0.3 for weight in pounds, 60.6 and 0.04 for BMI, and 40.8 and .03 for the obesity indicator.

b) NLSY: Instruments used are: sibling BMI, sibling age and gender. The F statistic and change in R2 in the first stage regressions are: 76.5 and .05 for weight in pounds, 77.9 and .06 for BMI, and 43.5 and .04 for the obesity indicator.

6) The sample is restricted to people aged 25 to 44. 
Table 4:

Received Disability Income, Females

\begin{tabular}{lcccc} 
& \multicolumn{2}{c}{ PSID } & \multicolumn{2}{c}{ NLSY79 } \\
\cline { 2 - 5 } & LP & 2SLS & LP & 2SLS \\
\hline Weight in Pounds & $.0002^{* *}$ & $.001^{*}$ & $.0001^{*}$ & $.0005 \#$ \\
& $(.0001)$ & $(.0004)$ & $(.0001)$ & .0003 \\
Height in Inches & & & & \\
& $(.0014$ & $-.0042^{*}$ & -.0002 & -.0018 \\
& & $(.002)$ & $(.001)$ & $(.0016)$ \\
\hline BMI & $.0014^{* *}$ & $.0058^{*}$ & $.0008^{*}$ & $.0028 \#$ \\
& $(.0005)$ & $(.0025)$ & $(.0003)$ & $(.0015)$ \\
\hline Indicator: Obesity & .0065 & $.0921^{*}$ & $.0117^{*}$ & $.0564^{*}$ \\
& $(.0062)$ & $(.0452)$ & .0047 & $(.0272)$ \\
\hline Number of Obs & 2,250 & 2,250 & 16,800 & 16,800
\end{tabular}

Notes:

1) Dependent variable is an indicator that equals 1 if the person received disability income, veteran's benefits, or workers' compensation, and equals 0 otherwise (in NLSY79, it also equals one if respondent's spouse received income through any of these sources).

2) Listed are coefficients and standard errors in parentheses

3) \# stands for significance at $10 \%$ level, * stands for significance at $5 \%$ level, ** stands for significance at $1 \%$ level.

4) Other variables that are included in the regressions are: Black dummy, Hispanic dummy, schooling, age, number of children, marriage dummies, region dummies.

5) Notes on 2SLS regressions:

a) PSID: Instruments used are: biological children's age, sex and BMI, whether children's information is missing, father's age and BMI, whether father's information is missing, mother's age and BMI, whether mother's information is missing. The F statistic and change in R2 in the first stage regressions are: 61.1 and 0.04 for weight in pounds, 61.8 and 0.04 for BMI, and 38.1 and .02 for the obesity indicator.

b) NLSY: Instruments used are: sibling BMI, sibling age and gender. The F statistic and change in R2 in the first stage regressions are: 98.1 and .05 for weight in pounds, 99.0 and .05 for BMI, and 73.9 and .04 for the obesity indicator.

6) The sample is restricted to people aged 25 to 44 . 


\section{Table 5:}

\section{Two-Year Work Limitations, Males}

\begin{tabular}{lcccc} 
& \multicolumn{2}{c}{ PSID } & \multicolumn{2}{c}{ NLSY79 } \\
\cline { 2 - 5 } & LP & 2SLS & LP & 2SLS \\
\hline Weight in Pounds & -.0001 & .0000 & .00003 & .0003 \\
& $(.0002)$ & $(.0008)$ & $(.00004)$ & $(.0002)$ \\
Height in Inches & .0018 & .0017 & -.0010 & -.0023 \\
& $(.0021)$ & $(.0051)$ & $(.0007)$ & $(.0011)$ \\
& & & & \\
\hline BMI & -.0005 & .0000 & .0002 & .0017 \\
& $(.0011)$ & $(.0056)$ & $(.0003)$ & $(.0012)$ \\
\hline Indicator: Obesity & -.0012 & .0156 & .0040 & .0175 \\
& $(.0116)$ & $(.0729)$ & $(.0025)$ & $(.0161)$ \\
\hline Number of Obs & 1,766 & 1,766 & 19,055 & 19,055
\end{tabular}

Notes:

1) Dependent variable is an indicator that equals 1 if the person has physical conditions that limit type or amount of work both this year and two years ago, and equals 0 otherwise.

2) Listed are coefficients and standard errors in parentheses

3) \# stands for significance at $10 \%$ level, * stands for significance at $5 \%$ level, ** stands for significance at $1 \%$ level.

4) Other variables that are included in the regressions are: Black dummy, Hispanic dummy, schooling, age, number of children, marriage dummies, region dummies.

5) Notes on 2SLS regressions:

a) PSID: Instruments used are: biological children's age, sex and BMI, whether children's information is missing, father's age and BMI, whether father's information is missing, mother's age and BMI, whether mother's information is missing. The F statistic and change in R2 in the first stage regressions are: 61.2 and 0.3 for weight in pounds, 60.6 and 0.04 for BMI, and 40.8 and .03 for the obesity indicator.

b) NLSY: Instruments used are: sibling BMI, sibling age and gender. The F statistic and change in R2 in the first stage regressions are: 76.5 and .05 for weight in pounds, 77.9 and .06 for BMI, and 43.5 and .04 for the obesity indicator.

6) The sample is restricted to people aged 25 to 44 . 


\section{Table 6:}

\section{Two-Year Work Limitations, Females}

\begin{tabular}{lcccc} 
& \multicolumn{2}{c}{ PSID } & \multicolumn{2}{c}{ NLSY79 } \\
\cline { 2 - 5 } & LP & 2SLS & LP & 2SLS \\
\hline Weight in Pounds & .0002 & .0006 & $.0002^{* *}$ & .0003 \\
& $(.0001)$ & $(.0006)$ & $(.00004)$ & $(.0002)$ \\
Height in Inches & & & & \\
& -.0014 & -.0031 & -.0008 & -.0014 \\
& $(.0017)$ & $(.0028)$ & $(.0009)$ & $(.0011)$ \\
\hline BMI & & & & \\
\hline Indicator: Obesity & $.0011 \#$ & .0034 & $.0009 * *$ & .0017 \\
& $(.0006)$ & $(.0035)$ & $(.0002)$ & $(.0011)$ \\
\hline Number of Obs & 2,211 & 2,211 & 16,472 & 16,472
\end{tabular}

Notes:

1) Dependent variable is an indicator that equals 1 if the person has physical conditions that limit type or amount of work both this year and two years ago, and equals 0 otherwise.

2) Listed are coefficients and standard errors in parentheses

3) \# stands for significance at $10 \%$ level, * stands for significance at $5 \%$ level, ** stands for significance at $1 \%$ level.

4) Other variables that are included in the regressions are: Black dummy, Hispanic dummy, schooling, age, number of children, marriage dummies, region dummies.

5) Notes on 2SLS regressions:

a) PSID: Instruments used are: biological children's age, sex and BMI, whether children's information is missing, father's age and BMI, whether father's information is missing, mother's age and BMI, whether mother's information is missing. The F statistic and change in R2 in the first stage regressions are: 61.1 and 0.04 for weight in pounds, 61.8 and 0.04 for BMI, and 38.1 and .02 for the obesity indicator.

b) NLSY: Instruments used are: sibling BMI, sibling age and gender. The F statistic and change in R2 in the first stage regressions are: 98.1 and .05 for weight in pounds, 99.0 and .05 for BMI, and 73.9 and .04 for the obesity indicator.

6) The sample is restricted to people aged 25 to 44 . 
Table 7:

Received Disability Income For Two Years, Males

\begin{tabular}{lcccc} 
& \multicolumn{2}{c}{ PSID } & \multicolumn{2}{c}{ NLSY79 } \\
\cline { 2 - 5 } & LP & 2SLS & LP & 2SLS \\
\hline Weight in Pounds & .0000 & .0001 & -.00001 & .0002 \\
& $(.0001)$ & $(.0004)$ & $(.00003)$ & $(.0002)$ \\
Height in Inches & & & & \\
& -.0009 & -.0015 & -.0003 & -.0013 \\
& $(.0011)$ & $(.0026)$ & $(.0005)$ & $(.0011)$ \\
\hline BMI & & & & \\
\hline Indicator: Obesity & .0053 & .013 & .0005 & .0162 \\
& $(.0006)$ & $(.0006)$ & $(.0002)$ & $(.0010)$ \\
\hline Number of Obs & 1,827 & 1,827 & 19,504 & 19,504
\end{tabular}

Notes:

1) Dependent variable is an indicator that equals 1 if the person received disability income, veteran's benefits, or workers' compensation this year and two years ago, and equals 0 otherwise (in NLSY79, it also equals one if respondent's spouse received income through any of these sources).

2) Listed are coefficients and standard errors in parentheses

3) \# stands for significance at $10 \%$ level, * stands for significance at $5 \%$ level, ** stands for significance at $1 \%$ level.

4) Other variables that are included in the regressions are: Black dummy, Hispanic dummy, schooling, age, number of children, marriage dummies, region dummies.

5) Notes on 2SLS regressions:

a) PSID: Instruments used are: biological children's age, sex and BMI, whether children's information is missing, father's age and BMI, whether father's information is missing, mother's age and BMI, whether mother's information is missing. The F statistic and change in R2 in the first stage regressions are: 61.2 and 0.3 for weight in pounds, 60.6 and 0.04 for BMI, and 40.8 and .03 for the obesity indicator.

b) NLSY: Instruments used are: sibling BMI, sibling age and gender. The F statistic and change in R2 in the first stage regressions are: 76.5 and .05 for weight in pounds, 77.9 and .06 for BMI, and 43.5 and .04 for the obesity indicator.

6) The sample is restricted to people aged 25 to 44 . 
Table 8:

Received Disability Income For Two Years, Females

\begin{tabular}{lcccc} 
& \multicolumn{2}{c}{ PSID } & \multicolumn{2}{c}{ NLSY79 } \\
\cline { 2 - 5 } & LP & 2SLS & LP & 2SLS \\
\hline Weight in Pounds & .0000 & .0002 & .00001 & $.0003^{*}$ \\
& $(0)$ & $(.0002)$ & $(.00003)$ & $(.0001)$ \\
Height in Inches & -.0007 & -.0014 & .00003 & $-.0014 \#$ \\
& $(.0007)$ & $(.0011)$ & $(.0005)$ & $(.0008)$ \\
& & & & \\
\hline BMI & .0001 & .0012 & .0001 & $.0019 *$ \\
& $(.0003)$ & $(.0014)$ & $(.0002)$ & $(.0008)$ \\
\hline Indicator: Obesity & -.0001 & .0216 & .0026 & $.0367 * *$ \\
& $(.0034)$ & $(.0253)$ & $(.0024)$ & $(.0141)$ \\
\hline Number of Obs & 2,250 & 2,250 & 16,834 & 16,834
\end{tabular}

Notes:

1) Dependent variable is an indicator that equals 1 if the person received disability income, veteran's benefits, or workers' compensation this year and two years ago, and equals 0 otherwise (in NLSY79, it also equals one if respondent's spouse received income through any of these sources).

2) Listed are coefficients and standard errors in parentheses

3) \# stands for significance at $10 \%$ level, * stands for significance at $5 \%$ level, ** stands for significance at $1 \%$ level.

4) Other variables that are included in the regressions are: Black dummy, Hispanic dummy, schooling, age, number of children, marriage dummies, region dummies.

5) Notes on 2SLS regressions:

a) PSID: Instruments used are: biological children's age, sex and BMI, whether children's information is missing, father's age and BMI, whether father's information is missing, mother's age and BMI, whether mother's information is missing. The F statistic and change in R2 in the first stage regressions are: 61.1 and 0.04 for weight in pounds, 61.8 and 0.04 for BMI, and 38.1 and .02 for the obesity indicator.

b) NLSY: Instruments used are: sibling BMI, sibling age and gender. The F statistic and change in R2 in the first stage regressions are: 98.1 and .05 for weight in pounds, 99.0 and .05 for BMI, and 73.9 and .04 for the obesity indicator.

6) The sample is restricted to people aged 25 to 44 . 